\title{
Square-wave Adsorptive Anodic Stripping Voltammetric Determination of Antidiabetic Drug Linagliptin in Pharmaceutical Formulations and Biological Fluids Using a Pencil Graphite Electrode
}

\author{
Ahmed. H. Naggar, ${ }^{* 1, * 2 \dagger}$ Gamal. A. Saleh, ${ }^{* 3}$ Mahmoud. A. OMar, ${ }^{* 4, * 5}$ Ahmed. M. Haredy, ${ }^{* 5}$ and \\ Sayed. M. DERAYEA $* 5$ \\ *1 Chemistry Department, College of Science and Arts, Jouf University, Al-Qurayyat, 75911, Kingdom of Saudi \\ Arabia \\ *2 Chemistry Department, Faculty of Science, Al-Azhar University, Assiut, 71524, Egypt \\ *3 Department of Pharmaceutical Analytical Chemistry, Faculty of Pharmacy, Assiut University, Assiut, Egypt \\ *4 Department of Pharmacognosy and Pharmaceutical Chemistry, College of Pharmacy, Taibah University, \\ Medinah, Kingdom of Saudi Arabia \\ *5 Analytical Chemistry Department, Faculty of Pharmacy, Minia University, Minia, Egypt
}

\begin{abstract}
A simple, sensitive, low-cost, quick and reliable square-wave anodic stripping voltammetric method is described for the determination of the antidiabetic drug Linagliptin (LNG) in pure form, tablets, and spiked human urine and plasma samples. Using a pencil graphite electrode (PGE), cyclic voltammetry (CV) was applied to study the electrochemical behavior of LNG. In a Teorell-Stenhagen buffer ( $\mathrm{pH}$ 5.5) containing $0.1 \mathrm{M} \mathrm{NaClO}_{4}$ as a supporting electrolyte, the LNG yields an irreversible well-defined oxidation peak at about $1.2 \mathrm{~V} v s . \mathrm{Ag} / \mathrm{AgCl}$ electrode. The various affecting factors, such as the $\mathrm{pH}$, buffer type, supporting electrolyte, accumulation potential, scan rate and accumulation time, were tested and optimized. Also, square-wave adsorptive anodic stripping voltammetric (SWAdASV) studies show that the peak current various linearly over the LNG concentration range of $0.24-5.20 \mu \mathrm{g} \mathrm{mL}^{-1}\left(R^{2}=0.9994\right)$. The detection and quantification limits were calculated to be 0.10 and $0.33 \mu \mathrm{g} \mathrm{mL} \mathrm{L}^{-1}$, respectively. The proposed procedure exhibits a good precision, selectivity, and stability and was applied successfully to determine the LNG in pharmaceutical formulations (tablets) and biological fluids (spiked human urine and plasma samples).
\end{abstract}

Keywords Linagliptin, pencil graphite electrode, square wave voltammetry, determination, pharmaceutical formulations, biological fluids

(Received December 16, 2019; Accepted January 31, 2020; Advance Publication Released Online by J-STAGE February 14, 2020)

\section{Introduction}

Diabetes mellitus (DM) is a chronic condition prevalent worldwide, which is characterized by increasing glucose concentrations in the bloodstream. DM causes serious damage to many systems in the body, particularly the nerves systems and blood vessels. It is estimated that more than 246 million individuals have diabetes, with this number expected to increase to 366 million until 2030. ${ }^{1}$ Linagliptin (LNG) which is chemically known as 8-[(3R)-3-aminopiperidin-1-yl]-7-(but-2yn-1-yl)-3-methyl-1-[(4-methyl quinazolin-2-yl)methyl]-3,7dihydro-1H-purine-2,6-dione (Scheme 1), with the empirical formula of $\mathrm{C}_{25} \mathrm{H}_{28} \mathrm{~N}_{8} \mathrm{O}_{2}$ and molecular weight 472.54 , it was approved in 2011 by the US Food and Drug Administration (FDA).

LNG is described for the treatment of type II diabetes in patients who cannot control their blood sugar levels alone., ${ }^{2,3}$ The antidiabetic activity of LNG aims to increase the amount of released insulin for better glycemic control through inhibiting

† To whom correspondence should be addressed.

E-mail: ahayoub@ju.edu.sa; ahnayoub@azhar.edu.eg dipeptidyl peptidase-4 (DPP-4), an enzyme which degrades the incretin endogenous hormones; glucagon-like peptide-I (GLP-I) and glucose-dependent insulin tropic polypeptide (GIP). ${ }^{3,4}$ LNG is orally administered as a single drug/daily as a 5-mg dose in adults and/or in combination with metformin or empagliflozin..$^{5,6}$

While reviewing literature, it was revealed that several methods exist to determine the LNG individually or in binary mixtures with other drugs either in bulk form, pharmaceuticals, and biological fluids. These methods include chromatographic, ${ }^{7-14}$<smiles>CC#Cn1c(N2CCC[C@@H](N)C2)nc2c1c(=O)n(Cc1nc(C)c3ccccc3n1)c(=O)n2C</smiles>

Scheme 1 Chemical structure of LNG. 
spectrophotometric ${ }^{15-19}$ and spectrofluorometric techniques. ${ }^{20,21}$ It should be noted that the literature survey shows that no official methods have been reported for the determination of LNG. ${ }^{19}$

From the review, most of the designated procedures for LNG quantification show a good linearity range with lower detection and quantification limit values, but it is still more expensive; sample pretreatment steps are tedious and complicated and need highly experienced and skilled persons. Due to LNG's significant medical importance, there is a persistent need to discover new analytical methods for its determination. Electroanalytical methods can be considered as an excellent alternative route since it is widely used for the trace analysis of pharmaceuticals in dosage forms and different biological fluids Among the electrochemical methods, stripping voltammetric techniques considered a very selective, fast response, very small detection limit $(\mathrm{ng} / \mathrm{mL})$ without the need to sample pretreatment steps. Also, voltammetry techniques accessories offer a wide selection range of inexpensive tools which make it more applicable. ${ }^{22-31}$ From our knowledge, there is only one electroanalytical method that was reported for the determination of LNG in the presence of glucose and metformin using a carbon paste electrode (CPE), which is modified with iron oxide nanoparticles $\left(\mathrm{Fe}_{2} \mathrm{O}_{3} \mathrm{NPs}\right){ }^{22}$ Pencil graphite electrodes (PGEs) are carbon-based electrodes that are recognized by their lowestcost commercial availability, good mechanical rigidity, ease of modification and disposability. Moreover, it was reported that PGE offers an easier way to regenerate the surface with simpler and faster polishing procedures than that used with common with other solid electrodes. ${ }^{29-34}$ The current work is a continuation of our efforts to determine the LNG as an example of DPP-4 inhibitors since we successfully determined LNG using spectrofluorimetry. ${ }^{21}$ In this article, a highly fluorescent product is produced upon the reaction of LNG with a fluorescamine reagent in an alkaline medium. LNG was determined over the concentration range of $0.2-2.0 \mu \mathrm{g} \mathrm{mL}^{-1}$ with a detection limit of $0.079 \mu \mathrm{g} \mathrm{mL} L^{-1}$. Herein, bare PGE was successfully utilized for the determination of LNG in pure form, pharmaceutical formulations (tablets) and biological fluids (spiked human urine and plasma samples) using square-wave anodic stripping voltammetry.

\section{Experimental}

\section{Apparatus}

Cyclic voltammetry $(\mathrm{CV})$ and square-wave adsorptive anodic stripping voltammetric (SWAdASV) experiments were conducted using EG\&G Princeton Applied Research (PAR Princeton, NJ, USA) Model 273A potentiostat, controlled by the Model 270/250 electrochemical software (Ver. 4.30) connected to a three-electrode cell were used for the measurements. A pencil graphite electrode (PGE) (ATI, B $2.0 \mathrm{~mm} \times 127 \mathrm{~L}$ made in Taiwan) was used as a working electrode; an $\mathrm{Ag} / \mathrm{AgCl}$ (saturated $\mathrm{KCl}$ ) as a reference electrode and finally a platinum wire was used as an auxiliary electrode. Mass transport was achieved with a Teflon-coated bar at approximately $400 \mathrm{rpm}$ using a magnetic stirrer (KIKA Labortechinik, Germany). All experiments were performed at room temperature in an electrochemical cell without removing the dissolved oxygen. All of the $\mathrm{pH}$ measurements were made using an iMeshbean pH-108 IA Pocket Pen Type LCD Screen pH Meter \& Digital Tester Hydro with ATC Function (Automatic Temperature Compensation) made in China.

\section{Reagents and materials}

All of the chemicals used were of analytical grade and their solutions were prepared by using double distilled water. Citric acid, sodium hydroxide, orthophosphoric acid, and hydrochloric acid were purchased from El-Nasr Chemical Co. (Cairo, Egypt). Teorell-Stenhagen buffer (which is a modified preparation of universal buffer $)^{35}$ was selected as a preferred medium in this current study $(I=0.1 \mathrm{M}, \mathrm{pH} 2.5-11.5)$. Teorell-Stenhagen buffer is composed of orthophosphoric acid, citric acid, and sodium hydroxide and the required $\mathrm{pH}$ was adjusted by $0.1 \mathrm{M}$ hydrochloric acid. LNG was supplied as a gift from EVA pharm lot. No: 24529 Cairo, Egypt. LNG stock solution was prepared by dissolving an appropriate amount of LNG in methanol and it was stored in a refrigerator. The required concentrations were prepared by daily serial dilution of the LNG stock solution using the same solvent. Trajenta ${ }^{\circledR}$ (LNG) produced by Boehringer Ingelheim Limited labeled to contain $5 \mathrm{mg}$ per tablet were purchased.

\section{Procedure}

General procedure for $L N G$ determination in pure form. The suggested procedure that adopted for recording cyclic and square-wave adsorptive anodic stripping voltammograms (SWAdASV) for LNG determination was as follows: the smoothed and cleaned PGE was immersed in a blank solution of Teorell-Stenhagen buffer ( $\mathrm{pH} 5.5$ ) containing $0.1 \mathrm{M} \mathrm{NaClO}_{4}$. While stirring, an accumulation potential was applied for a certain accumulation time. At the end of stirring, the stirrer was stopped, and the solution could become quiescent for $10 \mathrm{~s}$ prior to the voltammetric scan in the potential range from +0.5 to $+1.7 \mathrm{~V}$. The same experiment was repeated in the presence of $2.36 \mu \mathrm{g} \mathrm{mL}^{-1} \mathrm{LNG}$ (Scheme 2). For each measurement, the tip of PGE was polished on a white paper until getting a newly smoothed contact surface. All experiments were performed at room temperature $\left(25 \pm 1^{\circ} \mathrm{C}\right)$.

Determination of $L N G$ in pharmaceutical formulation (tablets). Ten tablets of Trajenta $^{\circledR}$ (5 mg LNG/tablet) were weighed, powdered and mixed well in a mortar. The specific weight of grounded tablets was calculated to prepare an LNG solution of $0.01 \mathrm{M}$, which was transferred into a $10-\mathrm{mL}$ calibrated flask, and then about $7 \mathrm{~mL}$ methanol was added. The contents were sonicated for $20 \mathrm{~min}$, and then the total volume was completed to $10-\mathrm{mL}$ by the same solvent. This solution was filtered, and an aliquot of the filtrate was transferred to a $10-\mathrm{mL}$ calibrated flask and the total volume was completed using methanol to obtain LNG tablets stock solution. Working solutions were prepared by taking suitable aliquots of the clear filtrate and diluting with methanol. A $75-\mu \mathrm{L}$ volume of diluted solutions $\left(1 \times 10^{-4} \mathrm{M}\right)$ was injected in the electrochemical cell containing $15 \mathrm{~mL}$ mixture of Teorell-Stenhagen buffer (pH 5.5) and $0.1 \mathrm{M}$ $\mathrm{NaClO}_{4}$, the voltammetric procedure was routine as before.

Determination of LNG in biological fluids. In this current study, we aimed to determine LNG in biological fluids (spiked human urine and plasma samples). These biological fluids were collected from healthy volunteers and used shortly after collection. Each of these samples needs to be pretreated before being used in LNG determination.

Spiked human urine sample pretreatment. For the determination of LNG in spiked human urine samples, urine was supplied from healthy volunteers. Each urine sample was centrifuged for $20 \mathrm{~min}$ at $4000 \mathrm{rpm}$ to get rid of protein residues, and then, the supernatant was taken. Then $1.50 \mathrm{~mL}$ of the resulting supernatant urine solution was added into an electrochemical cell and completed to $15 \mathrm{~mL}$ with the buffer before the addition of LNG, and the voltammetric procedure was conducted as 


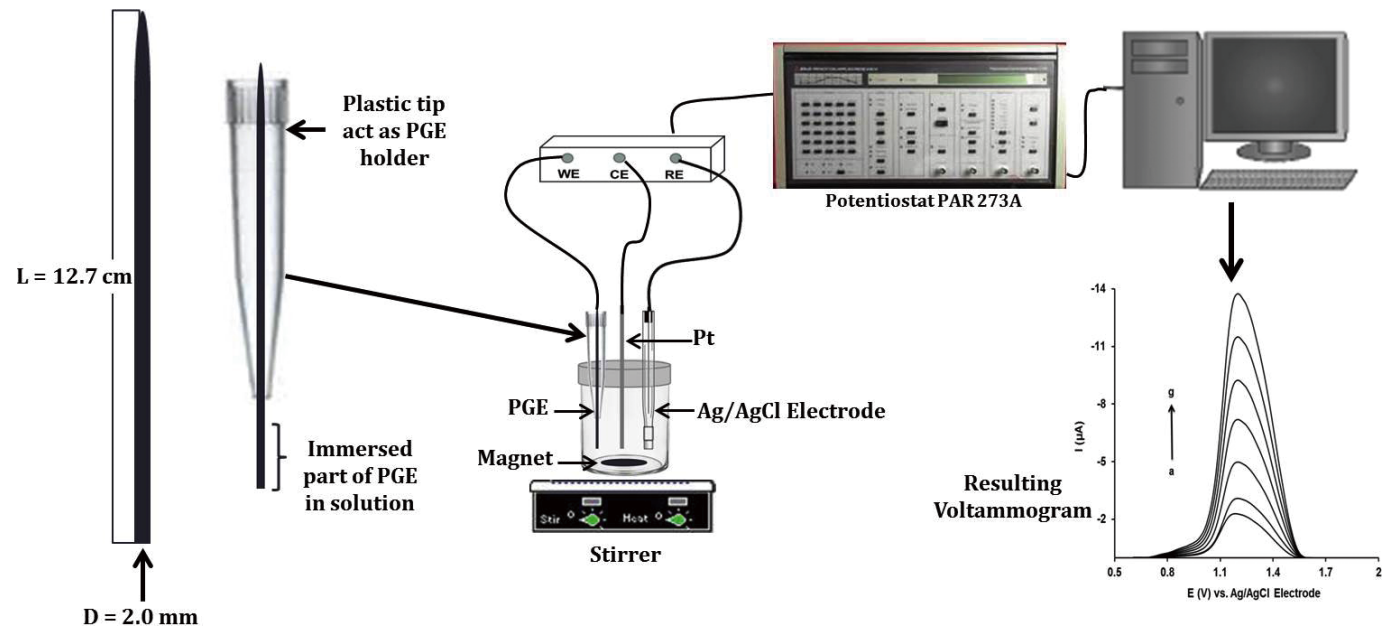

Scheme 2 Description of applied SWAdASV for LNG determination.

described before.

Spiked human plasma sample pretreatment. After centrifuging the plasma for $30 \mathrm{~min}$ at $4000 \mathrm{rpm}$ by using a tabletop highspeed universal harmonic centrifuge, $12000 \mathrm{rpm}$ Model PLC012 made in Taiwan. Then, $0.5 \mathrm{~mL}$ of the supernatant spiked plasma, $0.5 \mathrm{~mL} 0.01 \mathrm{M} \mathrm{LNG}$ and $1 \mathrm{~mL}$ acetonitrile were taken and completed to $5 \mathrm{~mL}$ by water. This mixture was centrifuged for $20 \mathrm{~min}$ at $4000 \mathrm{rpm}$. After the finishing the centrifuge, an aliquot of the produced plank plasma solution was injected into an electrochemical cell and the voltammetric procedure was conducted, as described before.

\section{Results and Discussion}

\section{Electrochemical behavior of $L N G$}

In current work, cyclic voltammetry was utilized to study the electrochemical behavior of LNG. Using bare PGE, LNG showed only one well-defined oxidation peak at about $+1.2 \mathrm{~V}$ in Teorell-Stenhagen buffer ( $\mathrm{pH} 5.5$ ) containing $0.1 \mathrm{M} \mathrm{NaClO}_{4}$. No peaks were observed in the reverse scan, suggesting that the LNG oxidation process is an irreversible one. The irreversible nature of LNG at PGE was further established by recording a cyclic voltammogram of $2.36 \mu \mathrm{g} \mathrm{mL}^{-1} \mathrm{LNG}$ at various scan rates values from 0.025 to $0.6 \mathrm{~V} / \mathrm{s}$ (Fig. 1A). As the scan rate increased, the peak potential was shifted to more positive values, which verified the irreversible nature of the LNG oxidation process. Figure 1B illustrates the influence of the square root of the studied scan rate values on the recorded peak current. It presents a linear relationship, which expressed as follows:

$$
I(\mu \mathrm{A})=140.9000 v^{1 / 2}(\mathrm{~V} / \mathrm{s})^{1 / 2}+0.6608\left(R^{2}=0.9982\right)
$$

This indicates that LNG oxidation is a diffusion-controlled process. ${ }^{36}$ Also, a linear relationship was obtained for the effect of the logarithm scan rate $(\log v)$ on the logarithm peak current $(\log I)$ (Fig. 1C(a)), with a slope of 0.4909 according to the following equations:

$$
\log I(\mu \mathrm{A})=0.4909 \log v(\mathrm{~V} / \mathrm{s})+2.1478\left(R^{2}=0.9986\right)
$$

The slope of 0.4909 is very close to the theoretically expected value of 0.5 for completely diffusion-controlled processes, ${ }^{37}$ which confirms that the LNG oxidation reaction is diffusion-
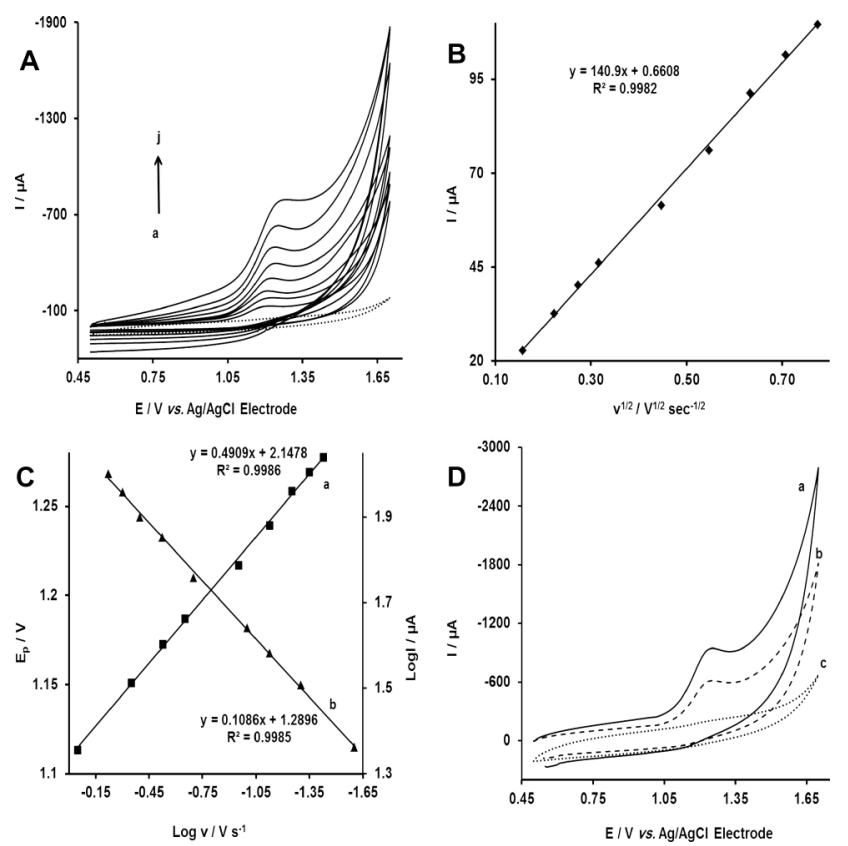

Fig. 1 (A) Typical cyclic voltammograms for $2.36 \mu \mathrm{gL}^{-1} \mathrm{LNG}$ oxidation using PGE at different scan rate values: (a) blank TeorellStenhagen buffer, (b) 0.025, (c) 0.05, (d) 0.075, (e) 0.1, (f) 0.2, (g) 0.3, (h) 0.4 , (i) 0.5 and (j) $0.6 \mathrm{~V} / \mathrm{s}$. (B) Linear relationship shows dependence of LNG oxidation peak current on the square root of studied scan rate values. (C) Linear relation between logarithm of studied scan rate values and: (a) logarithm LNG peak current values, and (b) recorded LNG peak potential. (D) Repetitive cyclic voltammogram of $2.36 \mu \mathrm{g} \mathrm{mL}^{-1} \mathrm{LNG}$ at the same PGE surface: 1st cycle (Cycle a), 2nd cycle (Cycle b) and 3rd cycle (Cycle c).

controlled processes. Moreover, the effect of the logarithm scan rate $(\log v)$ on the recorded peak potential $\left(E_{\mathrm{p}}\right)$ was examined. Figure $1 \mathrm{C}(\mathrm{b})$ shows the obtained straight line for this effect and it can be expressed as:

$$
E_{\mathrm{p}}=0.1086 \log v(\mathrm{~V} / \mathrm{s})+1.2896\left(R^{2}=0.9985\right)
$$

It is appropriate to confirm that the electrochemical oxidation of LNG was a diffusion-adsorption-controlled process. Since 
<smiles>CC#Cn1c(N2CCC[C@H](N)C2)nc2c1c(=O)n(Cc1nc(C)c3ccccc3n1)c(=O)n2C</smiles>

Scheme 3 Suggested scheme for the electrochemical reaction of LNG.

the electrochemical reaction of LNG is completely irreversible, the relationship of $E_{\mathrm{p}} v s . \log v$ can be expressed according to Laviron theory, which usually applied for completely irreversible electrode processes ${ }^{38}$ :

$$
E_{\mathrm{p}}=E^{\circ}+\left(\frac{2.303 R T}{\alpha n F}\right) \log \left(\frac{R T K_{\mathrm{s}}}{\alpha n F}\right)+\left(\frac{2.303 R T}{\alpha n F}\right) \log v
$$

Here $\alpha$ is the transfer coefficient, $K_{\mathrm{s}}$ is the standard rate constant of the reaction, $n$ is the number of electrons transferred, $v$ the scan rate and $E^{\circ}$ is the formal peak potential. Other symbols have the usual meaning, where $R$ is the universal gas constant $\left(8.314 \mathrm{~J} \mathrm{~mol}^{-1} \mathrm{~K}^{-1}\right), \quad T$ is the absolute temperature $(298 \mathrm{~K})$ and $F$ is the Faraday constant $\left(96480 \mathrm{C} \mathrm{mol}^{-1}\right)$. Thus, the value of $\alpha n$ can be easily calculated from the slope of $E_{\mathrm{p}} v s$. $\log v$ according to the following equation:

$$
\text { Slope }=\frac{2.303 R T}{\alpha n F}
$$

The linear relationship presented in Fig. $1 \mathrm{C}(\mathrm{b})$ has a slope value of 0.1086 , and the $(\alpha n)$ values were calculated to be 0.545 . If $\alpha$ is approximately 0.5 , the number of transferred electrons in the LNG oxidation process will be equal to 1.09. This value is very close to the results shown in the proposed oxidation mechanism of LNG (Scheme 3), where one electron is involved in LNG oxidation:

According to the above data, we can confirm that the irreversible oxidation of LNG at PGE is mostly controlled by diffusion accompanied by some adsorption support. This behavior was confirmed by recording successive cyclic voltammograms of LNG at PGE (Fig. 1D). First cycle shows the oxidation peak of $\mathrm{LNG}$ at about $1.2 \mathrm{~V} v \mathrm{vs}$. $\mathrm{Ag} / \mathrm{AgCl}$ electrode (Cycle a), but the 2nd cycle shows a significant decrease in the peak current (Cycle b), which disappeared in the 3rd one (Cycle c). This can be attributed to that the yield of LNG oxidation tends to be stacked on the PGE surface, which hinders any further diffusion of LNG oxidation product to the PGE surface, thereby causing a significant decrease in the anodic peak current. So, as we indicated before, after each measurement, the tip of PGE was polished on a white paper until getting a newly smoothed contact surface.

\section{Optimization of experimental parameters}

In this current study, different experimental parameters which affect the resulting oxidation peak current of LNG were studied using an optimized SWAdASV procedure. These parameters include the $\mathrm{pH}$, buffer type, supporting electrolyte and concentration.

The influence of the $\mathrm{pH}$ on the LNG oxidation process was studied. For this purpose, Teorell-Stenhagen buffer was used in the $\mathrm{pH}$ range from 2.5 to 11.5. As can be seen in Fig. 2 (A and
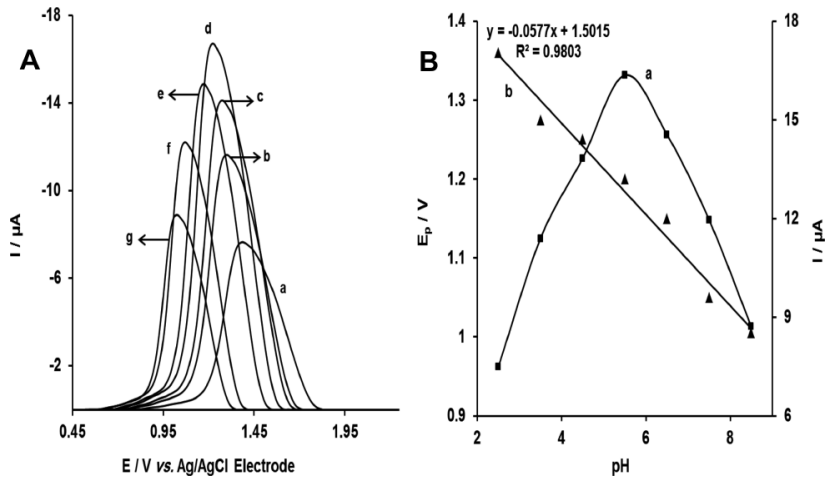

Fig. 2 (A) Typical SWAdAS voltammograms for $2.36 \mu \mathrm{g} \mathrm{mL}$ LNG oxidation using PGE in Teorell-Stenhagen buffer at different $\mathrm{pH}$ values: (a) 2.5 , (b) 3.5 , (c) 4.5 , (d) 5.5 , (e) 6.5 , (f) 7.5 , and (g) 8.5 . (B) (a) Shows the dependence of the $2.36 \mu \mathrm{g} \mathrm{mL}^{-1} \mathrm{LNG}$ oxidation peak current values on studied $\mathrm{pH}$ values. (b) A linear relationship between studied $\mathrm{pH}$ values and corresponding $2.36 \mu \mathrm{g} \mathrm{mL}^{-1} \mathrm{LNG}$ oxidation peak potential.

$\mathrm{B}(\mathrm{a}))$, the oxidation peak current of $2.36 \mu \mathrm{g} \mathrm{mL} \mathrm{L}^{-1} \mathrm{LNG}$ increases with increasing $\mathrm{pH}$ value until it reaches 5.5 , and then decreases when the $\mathrm{pH}$ increases from 5.5 to 8.5 . At more $\mathrm{pH}$ values, the oxidation peak of LNG is approximately disappeared. So, $\mathrm{pH} 5.5$ was adopted as the optimum $\mathrm{pH}$ for subsequent investigations. Also, Fig. 2 (A and $\mathrm{B}(\mathrm{b})$ ) shows that with increasing $\mathrm{pH}$ values, LNG oxidation peak potential shifts to low positive values, indicating that protons have taken part in the electrode reaction process of LNG. The showed linearity between recorded peak potential and studied $\mathrm{pH}$ values obeys the following equation:

$$
E_{\mathrm{p}}=-0.0557 \mathrm{pH}+1.5015\left(R^{2}=0.9803\right)
$$

The slope of this equation is found to be $0.0557 \mathrm{~V} / \mathrm{pH}$. This closeness of the slope to the expected theoretical value of $0.059 \mathrm{~V} / \mathrm{pH}$ suggests that the electrons transferred in the LNG oxidation process are equal to that of the hydrogen ions taking part in the electrode reaction. ${ }^{39}$

It is well known that the voltammetric procedure for an analyte determination is usually significantly influenced by the buffer type used in such a procedure. Consequently, several buffer types of the selected $\mathrm{pH}$ value $(\mathrm{pH} 5.5)$ were evaluated to determine the LNG at PGE. These buffers include TeorellStenhagen, acetate, succinate, and citrate. Regarding the highest electroanalytical current and best square-wave peak shape, Teorell-Stenhagen buffer ( $\mathrm{pH}$ 5.5) gives the best result, which in turn was selected as optimal for subsequent experimental work described in the current article (Fig. 3). 


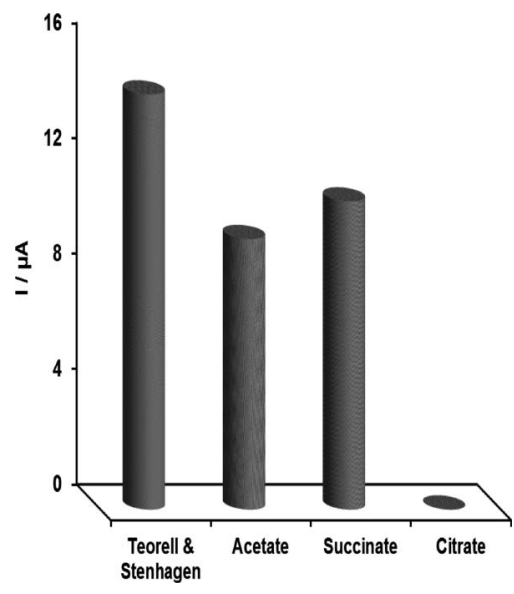

Fig. 3 Effect of buffer type on the voltammetric peak current of $2.36 \mu \mathrm{g} \mathrm{mL}^{-1} \mathrm{LNG}$ using different buffer types (pH 5.5) using PGE.

The influence of the type of supporting electrolyte on the suggested procedure for LNG determination was studied; $0.1 \mathrm{M}$ of $\mathrm{KCl}, \mathrm{NaNO}_{3}$, and $\mathrm{NaClO}_{4}$ were added individually to TeorellStenhagen ( $\mathrm{pH} 5.5)$ to evaluate the occurred change in the $2.36 \mu \mathrm{g} \mathrm{mL}^{-1} \mathrm{LNG}$ oxidation current. Upon the addition of

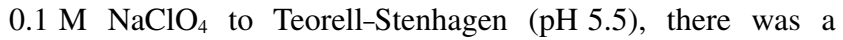
noticeable increase in the measured current value by about $40 \%$. The same behavior was obtained using $\mathrm{KCl}$ or $\mathrm{NaNO}_{3}$, but it still lower than $\mathrm{NaClO}_{4}$. We can assume that the presence of a $\mathrm{NaClO}_{4}$ increase LNG charge transfer occurred through the cell and its ability to be adsorbed on PGE surface moreover other electrolytes used. ${ }^{40}$ So, $\mathrm{NaClO}_{4}$ was selected as a preferred supporting electrolyte for further studies. We assumed that the $\mathrm{NaClO}_{4}$ concentration is also effective, and so it was studied by changing the $\mathrm{NaClO}_{4}$ concentration from 0.05 to $0.4 \mathrm{M}$. It was found that the presence of $0.1 \mathrm{M} \mathrm{NaClO}_{4}$ in the electrochemical cell containing Teorell-Stenhagen buffer ( $\mathrm{pH}$ 5.5) gave the best results, so it was chosen as the optimum one.

\section{Optimization of instrumental parameters}

Figure 4A shows the effect of the accumulation potential $\left(E_{\text {acc }}\right)$ on the $2.36 \mu \mathrm{g} \mathrm{mL}^{-1} \mathrm{LNG}$ oxidation peak current. The examined accumulation potential range was varied from 0.0 to $+1.0 \mathrm{~V}$. The experiments proved that in the Teorell-Stenhagen buffer ( $\mathrm{pH} 5.5)$, the peak current was increased with a positive shifting starting potential in the range from +0.0 to $+0.5 \mathrm{~V}$, and then decreased with positive shifting from +0.5 to $+1.0 \mathrm{~V}$. The peak current has its maximum value at the initial potential of $+0.5 \mathrm{~V}$, which was used in subsequent examinations of other decencies.

Two concentrations of LNG ( 0.473 and $4.725 \mu \mathrm{g} \mathrm{mL}-1)$ were used to examine the effect of time on the LNG oxidation peak current (Fig. 4B). With increasing accumulation time from $10 \mathrm{~s}$ up to $300 \mathrm{~s}$, it was noticed that the recorded peak current was increased linearly and then gradually decreased with increasing accumulation time more than $300 \mathrm{~s}$. This may have occurred due to saturation of the PGE surface with the adsorbed layer of LNG.

Since the proposed methodology for LNG determination is square-wave voltammetry (SWV), it is important to study the effect of the frequency and the pulse amplitude. This can be attributed to their influence on the capacitive current generation at higher values of these two factors, which in turn cause distortion in the SWV curves and decrease its sensitivity. ${ }^{41-43}$
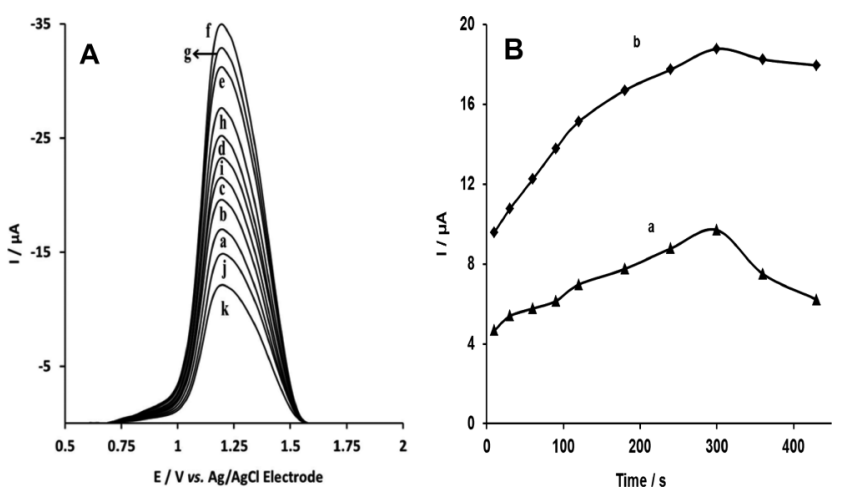

Fig. 4 (A) Typical SWAdAS voltammograms for the oxidation peak of $2.36 \mu \mathrm{g} \mathrm{mL}-1$ LNG using PGE in Teorell-Stenhagen buffer ( $\mathrm{pH} 5.5$ ) at $60 \mathrm{~s}$ accumulation time at different accumulation potential values: (a) 0.0 , (b) 0.1 , (c) 0.2 , (d) 0.3, (e) 0.4, (f) 0.5, (g) 0.6, (h) 0.7, (i) 0.8, (j) 0.9 , and (k) $1.0 \mathrm{~V}$. (B) Effect of accumulation time on (a) 0.473 and (b) $4.725 \mu \mathrm{g} \mathrm{mL}^{-1}$ LNG in Teorell-Stenhagen buffer (pH 5.5) containing $0.1 \mathrm{M} \mathrm{NaClO}_{4}$ at accumulation potential $+0.5 \mathrm{~V}$ using PGE.

A study of the effect of frequency was investigated at range of $10-100 \mathrm{~Hz}$. The peak gradually increased up to $60 \mathrm{~Hz}$ due to the increase of the scan rate, but at the highest values, the peak shape was distorted. Thus, $60 \mathrm{~Hz}$ was chosen as the optimum condition in this method.

Finally, in this section, we mention that the pulse amplitude was studied between 10 and $100 \mathrm{mV}$. The peak also increased upon an increase of the pulse amplitude up to $50 \mathrm{mV}$, but again at highest values the peak shape was distorted. Thus, $50 \mathrm{mV}$ was chosen for all subsequent studies.

\section{Analytical application}

Calibration curve. In order to study the feasibility of the proposed procedure for the analytical determination of LNG, the relationship between the anodic peak current and the LNG concentration was studied using SWV. SWV is preferred to be applied in the current article because of its greater analysis speed and fewer problems related to blocking the electrode surface due to a lower consumption of electroactive species. Moreover, in comparison to other voltammetric techniques, SWV shows the lowest detection limit, since the obtained signal using SWV is about 3 and 4-times higher than that of other techniques. ${ }^{44-46}$ Herein, SW voltammograms for LNG determination were recorded 10 times under the optimized conditions at PGE. The oxidation peak currents were found to be linearly proportional to the LNG concentrations over the range from 0.24 to $5.20 \mu \mathrm{g} \mathrm{mL}^{-1}$ in Teorell-Stenhagen ( $\mathrm{pH} 5.5$ ) consist of $0.1 \mathrm{M} \mathrm{NaClO}_{4}$. A deviation from linearity was observed at higher LNG concentrations, due to the adsorption of LNG or its oxidation product on the electrode surface. Figure 5A shows the typical SW voltammogram of different LNG concentrations under the optimized conditions method, while Fig. 5B represents a calibration plot of the same voltammogram. The constructed calibration curve can be expressed by the following equation:

$$
I(\mu \mathrm{A})=2.0092 \mathrm{LNG}\left(\mu \mathrm{g} \mathrm{mL} L^{-1}\right)+1.7458\left(R^{2}=0.9994\right)
$$

The good linearity of the constructed calibration graph can be seen by the highest value of the correlation coefficient. Also, the accuracy and precision were determined by calculating the 

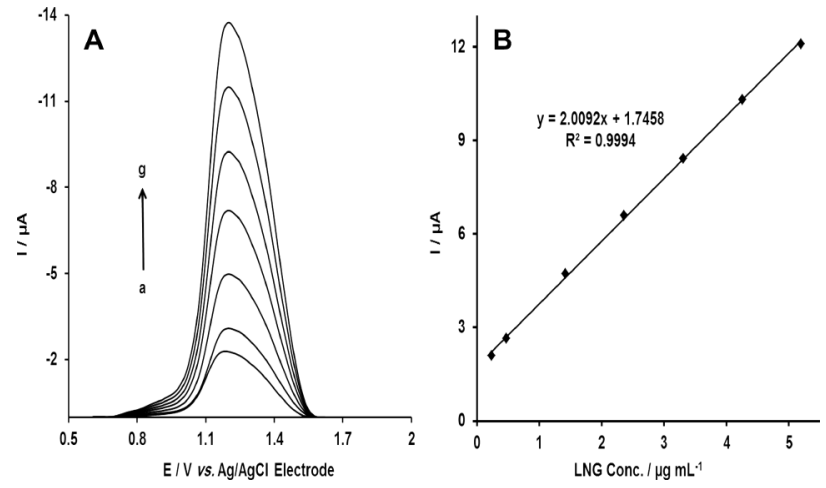

Fig. 5 (A) Typical SWAdAS voltammograms of LNG electrooxidation obtained at PGE in Teorell-Stenhagen buffer ( $\mathrm{pH}$ 5.5) containing $0.1 \mathrm{M} \mathrm{NaClO}_{4}$. LNG concentrations are: (a) 0.236, (b) 0.473 , (c) 1.418 , (d) 2.363 , (e) 3.308 , (f) 4.253 , and (g) $5.198 \mu \mathrm{g} \mathrm{mL}{ }^{-1}$. (B) The corresponding calibration plots.

Table 1 Regression data of calibration plot for LNG at PGE in Teorell-Stenhagen buffer ( $\mathrm{pH} 5.5$ ) containing $0.1 \mathrm{M} \mathrm{NaClO}_{4}$

\begin{tabular}{lc}
\hline \multicolumn{1}{c}{ Parameter } & Value \\
\hline Linearity range/ $\mu \mathrm{g} \mathrm{mL}^{-1}$ & $0.24-5.20$ \\
$\mathrm{LLOD} / \mu \mathrm{g} \mathrm{mL}^{-1}$ & 0.10 \\
$\mathrm{LLOQ} / \mu \mathrm{g} \mathrm{mL}^{-1}$ & 0.33 \\
Intercept $(\mu \mathrm{A}) \pm \mathrm{SD}$ & $1.7457 \pm 0.0669$ \\
$\mathrm{Slope}\left(\mu \mathrm{A} \mu \mathrm{g}^{-1} \mathrm{~mL}\right) \pm \mathrm{SD}$ & $2.0092 \pm 0.0221$ \\
$\mathrm{RSD}, \%$ & 1.55 \\
Correlation coefficient, $R^{2}$ & 0.9994 \\
Intra-day precision $(n=10)$, recoveries $(\%)$ for & $93.92-101.11$ \\
$\quad$ studied LNG concentrationsa & \\
Inter-day precision, 5 days, $(n=50)$ recoveries & $95.86-106.62$ \\
$\quad(\%)$ for studied LNG concentrationsa & \\
Intra-day precision $(n=10), \mathrm{RSD}(\%)$ for studied & 2.62 \\
$\quad$ LNG concentrations & \\
Inter-day precision, 5 days, $(n=50) \mathrm{RSD}(\%)$ for & 4.60 \\
$\quad$ studied LNG concentrations & \\
\hline
\end{tabular}

a. Studied LNG concentrations are 1.42, 3.31, and $5.20 \mu \mathrm{gL}^{-1}$.

recovery \% relative standard deviation (RSD) which was is presented in Table 1. The low value of \% RSD shows the good precision and accuracy of the method.

The lower limit of detection (LLOD) and quantification (LLOQ) were calculated using the following equations: LLOD $=3 \sigma / \mathrm{b}$ and LLOQ $=10 \sigma / \mathrm{b}$, where $\sigma$ is the standard deviation of the intercept and $b$ is the slope of the calibration curve. ${ }^{24,25,28}$ The regression data of the obtained calibration plot and the calculated LLOD and LLOQ for ten repeated determinations of LNG are presented in Table 1.

Table 2 illustrates a comparison of some analytical terms related to the proposed method and other analytical methods used for the LNG determination. The tabulated data show that the obtained results using the proposed method are very close, or even better than, the results obtained by other reported classical methods. To the best of our knowledge, the literature showed only one article concerning the electroanalytical determination of $\mathrm{LNG},{ }^{22}$ where carbon paste electrode (CPE) is modified with iron oxide nanoparticles $\left(\mathrm{Fe}_{2} \mathrm{O}_{3} \mathrm{NPs}\right)$ and it was applied as an electrochemical sensor for LNG determination. There is no doubt the use of metallic nanoparticles as an electrode modifier increases the electroanalytical procedure
Table 2 Comparison of the sensitivity of the developed method with other analytical methods used for LNG determination

\begin{tabular}{lcccc}
\hline \multirow{2}{*}{ Method } & $\begin{array}{c}\text { Linearity range/ } \\
\mu \mathrm{g} \mathrm{mL} \mathrm{mL}^{-1}\end{array}$ & $\begin{array}{c}\text { LLOD/ } \\
\mu \mathrm{g} \mathrm{mL}^{-1}\end{array}$ & $\begin{array}{c}\text { LLOQ/ } \\
\mu \mathrm{g} \mathrm{mL}{ }^{-1}\end{array}$ & Ref. \\
\hline Chromatography & $5.00-30.00$ & 0.025 & 0.080 & 7 \\
& $0.25-2.00$ & 0.020 & 0.067 & 8 \\
& $0.17-1.70$ & 0.057 & 0.172 & 9 \\
& $2.50-80.00$ & 0.730 & 2.440 & 10 \\
& $2.00-50.00$ & 0.490 & 1.500 & 11 \\
& $0.50-16.00$ & 0.120 & 0.360 & 12 \\
Spectrophotometric & $1.00-50.00$ & 0.300 & 1.000 & 13 \\
& $5.00-30.00$ & 0.230 & 0.780 & 15 \\
& $5.00-30.00$ & 0.770 & 2.340 & 15 \\
& $1.00-11.00$ & - & - & 16 \\
& $2.50-25.00$ & - & - & 17 \\
& $10.00-18.00$ & - & - & 18 \\
Spectrofluorometry & $5.00-25.00$ & 0.247 & 0.748 & 19 \\
& $10.00-110.00$ & 0.840 & 8.010 & 20 \\
Voltammetry & $0.20-2.00$ & 0.079 & 0.241 & 21 \\
& $0.03-86.00$ & 0.008 & 0.026 & 22 \\
& $0.24-5.20$ & 0.100 & 0.330 & This work \\
\hline
\end{tabular}

sensitivity, resulting in the lowering of LLOD and LLOQ. But the application of CPE as a working electrode has crucial disadvantages of aging effects that seriously limit its lifetime in addition to errors resulting from surface fouling. ${ }^{47}$ Also, and from an economical view, we can ensure that our procedure for LNG voltammetric determination is better since we use PGE as a working electrode, which is characterized as the lowest cost, ease of availability, good mechanical rigidity and it gives results with high repeatability values. Although the suggested method is less sensitive than that previously reported for the LNG voltammetric determination, ${ }^{22}$ the sensitivity achieved is fully sufficient to determine LNG either in bulk solutions, pharmaceutical formulations or in spiked biological samples. Moreover, using the proposed method LNG was determined at a short time of analysis with no need for complex extraction steps. Validation of the proposed method. The repeatability of the proposed method was investigated by recording the peak oxidation current for three different concentrations of LNG (1.42, 3.31 and $\left.5.20 \mu \mathrm{g} \mathrm{mL}^{-1}\right)$. Recovery measurements of these concentrations were calculated through their repetitive determination on the same day (an intra-day) and after five days (an inter-day). Under the optimum conditions and using the standard addition method for 10 repetitive measurements, the recovery and RSD proposed were calculated, and are tabulated in Table 1. Herein, the tabulated results confirm that the procedure for LNG voltammetric determination has good repeatability and reproducibility within its optimized quantitation limits.

Interference studies. To show the importance of the proposed procedure, it is important to investigate the selectivity of PGE toward LNG determination in the presence of different foreign species. In Teorell-Stenhagen ( $\mathrm{pH} 5.5)$ containing $0.1 \mathrm{M}$ $\mathrm{NaClO}_{4}$, the oxidation peak current of $2.36 \mu \mathrm{g} \mathrm{mL} \mathrm{L}^{-1} \mathrm{LNG}$ was recorded in both the absence and presence of studied interferences. The studied interferences included some inorganic salts (like $\mathrm{Cu}^{2+}, \mathrm{K}^{+}, \mathrm{Na}^{+}, \mathrm{Cl}^{-}, \mathrm{Zn}^{2+}$ ) and some excipients which usually exist in dosage forms (like starch, dextrose, and ascorbic acid). Regarding LNG, metformin is sometimes added to LNG in pharmaceutical formulations, so it is important to study if it can interfere with LNG determination using the proposed procedure. The tolerance limit for studied interferences was 

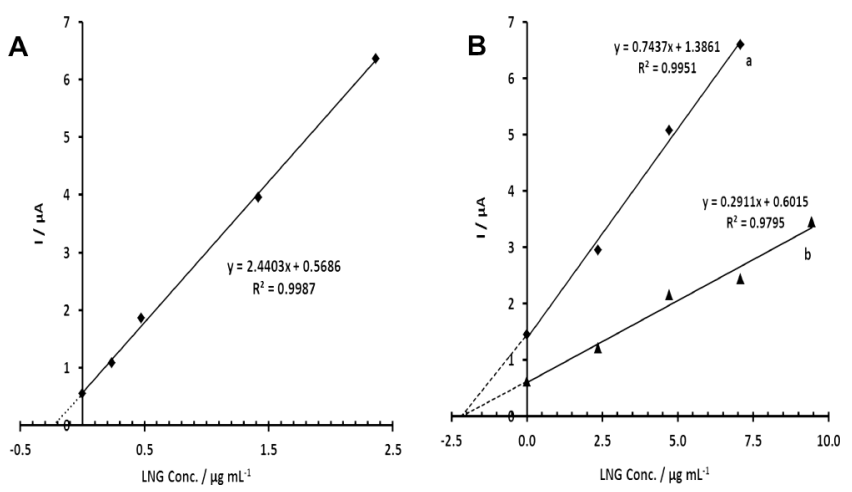

Fig. 6 Constructed calibration graph using standard addition method for direct determination of LNG in (A) Trajenta ${ }^{\circledR}$ tablets (containing $5 \mathrm{mg}$ LNG per tablet) and (B) spiked biological fluids: (a) urine and (b) plasma samples.

Table 3 Application of the proposed method for the analysis of Trajenta ${ }^{\circledR}$ tablets ( $5 \mathrm{mg}$ of LNG per tablet) by both the proposed and the reported methods ${ }^{1}$

\begin{tabular}{lcc}
\hline Parameter & Reported method & Proposed method \\
\hline Recovery, \% & 99.13 & 98.31 \\
SD, \% & 1.09 & 1.25 \\
$t$-value & - & 1.70 \\
$F$-value $^{\mathrm{b}}$ & - & 0.87 \\
\hline
\end{tabular}

a. The value is the mean of five determinations for both methods. b. Tabulated values at $95 \%$ confidence limit are $t=2.306, F=6.338$.

considered to be the maximum concentration of foreign substances that caused a relative error of less than $5 \%$ under the optimum conditions. ${ }^{27}$ For all studied interferences, no significant change was observed either in the recorded peak potential or current of LNG. The obtained results show recoveries in the range from 94.82 to $110.43 \%$ for $2.36 \mu \mathrm{g} \mathrm{mL}^{-1}$ LNG solution, indicating that there was no matrix interference with LNG by the proposed SWV method using PGE. So, we can assume that the proposed method offers high selectivity for the determination of LNG.

Analytical application of proposed method. Finally, Fig. 6 shows the constructed graph for the standard addition method which was used to determine the unknown concentration of Trajenta $^{\circledR}$ in tablets and biological fluids (urine and plasma samples). The mean recovery values were 98.31, 92.80, and $92.69 \%$, respectively. The results of the dosage form were compared statistically with those of the reported method $^{48}$ at a 95\% confidence level, as presented in Table 3. No significant difference was found between the theoretical and calculated values of the $t$ - and $F$-tests, which indicate a good level of precision and accuracy of the proposed methods.

\section{Conclusion}

In this paper, we introduce an alternative electrochemical sensor for the voltammetric determination of LNG. The proposed procedure is characterized as being simple, direct, sensitive, cheap, quick and reliable. The method was applied successfully to determine LNG in tablets and spiked biological fluids (spiked plasma and urine samples) with good recovery, precision, and accuracy. Thanks to the simplicity and selectivity of the proposed method, it can be applied easily to the determination of LNG regarding various research aspects like at quality control centers and pharmaceutical research authorities.

\section{References}

1. S. S. Aher, S. P. Gajare, and R. B. Saudagar, Res. J. Pharma. Technol., 2017, 10, 3233 .

2. J. J. Neumiller and S. M. Setter, Clin. Ther, 2012, 34, 993.

3. A. Mari, W. M. Sallas, Y. L. He, C. Watson, M. LiguerosSaylan, B. E. Dunning, C. F. Deacon, J. J. Holst, and J. E. Foley, J. Clin. Endocrinol. Metab., 2005, 90, 4888.

4. B. Ahrén, M. Landin-Olsson, P. A. Jansson, M. Svensson, D. Holmes, and A. Schweizer, J. Clin. Endocrinol. Metab., 2004, 89, 2078.

5. E. D. Deeks, Drugs, 2012, 72, 1793.

6. T. Jojima, T. Tomotsune, T. Iijima, K. Akimoto, K. Suzuki, and Y. Aso, Diabetol. Metab. Syndr., 2016, 8, 1.

7. L. R. Badugu, Am. J. Pharm. Tech. Res., 2012, 2, 463.

8. M. Attimarad, S. H. Nagaraja, B. E Aldhubaib, A. Nair, and K. N. Venugopala, Indian J. Pharm. Edu. Res., 2014, $48,45$.

9. A. Salapaka, K. B. Bonige, R. B. Korupolu, T. C. Reddy, K. C. Reddy, N. Sreenivas, H. K. Sharma, and U. K. Ray, Electrophoresis, 2019, 40, 1066.

10. R. I. El-Bagary, E. F. Elkady, and B. M. Ayoub, Int. J. Biomed. Sci., 2013, 8, 209.

11. M. F. Abdel-Ghany, O. Abdel-Aziz, M. F. Ayad, and M. M. Tadros, Acta Chromatogr., 2017, 29, 448.

12. B. M. Ayoub, RSC Adv., 2015, 5, 95703.

13. S. S. Mourad, E. I. El-Kimary, D. A. Hamdy, and M. A. Barary, J. Chromatogr. Sci., 2016, 54, 1560.

14. A. Hanafy and H. Mahgoub, J. Chromatogr. Sci., 2016, 54, 1573.

15. R. I. El-Bagary, E. F. Elkady, and B. M. Ayoub, Int. J. Biomed. Sci., 2013, 9, 41.

16. S. Gajare, A. Zalte, and R. B. Saudagar, Asian J. Pharm. Anal., 2017, 7, 79.

17. O. M. Abdalla, A. M. Abdel-Megied, A. S. Saad, and Sh. S. Soliman, Spectrochim. Acta, Part A, 2018, 203, 112.

18. S. Gajare, V. Das, A. Sambherao, A. Zalte, and R. B. Saudagar, Asian J. Pharm. Anal., 2017, 7, 141.

19. S. Banik, P. Karmakar, and Md. A. H. Miah, Bangladesh Pharm. J., 2015, 18, 163.

20. R. El-Bagary, E. Elkady, and B. M. Ayoub, Eur. J. Chem., 2014, 5, 380.

21. M. A. Omar, A. M. Haredy, G. A. Saleh, A. H. Naggar, and S. M. Derayea, Microchem. J., 2019, 148, 555.

22. M. A. El-Shal, Sh. M. Azab, and H. A. M. Hendawy, Bull. Nat. Res. Centr., 2019, 43, 95.

23. S. Cheraghi, M. A. Taher, M. Bijad, and H. Sadeghifar, Curr. Anal. Chem., 2017, 13, 5.

24. O. A. Farghaly, M. A. Taher, A. H. Naggar, and A. Y. ElSayed, J. Pharm. Biomed. Anal., 2005, 38, 14.

25. A. H. Naggar, A. Kotb, A. A. Gahlan, and A. Y. El-Sayed, Elixir Appl. Chem., 2014, 77, 29391.

26. A. Hosny Naggar, M. ElKaoutit, I. Naranjo-Rodriguez, A. Y. El-Sayed, and J. L. Hidalgo-Hidalgo de Cisneros, Talanta, 2012, 89, 448.

27. M. A. El-Shal and H. A. M. Hendawy, Anal. Sci., 2019, 35, 189.

28. E. Nagles and O. García-Beltrán, Anal. Sci., 2018, 34, 1171.

29. F. A. M. Abdel-aal, A. H. Rageh, M. I. Said, and Gamal A. Saleh, Anal. Chim. Acta, 2018, 1038, 29. 
30. G. A. Saleh, H. F. Askal, I. H. Refaat, A. H. Naggar, and F. A. M. Abdel-aal, Arab. J. Chem., 2016, 9, 143.

31. G. A. Saleh, H. F. Askal, I. H. Refaat, and F. A. M. Abdelaal, Bull. Chem. Soc. Jpn., 2015, 88, 1291.

32. A. A. Al-Rashdi, O. A. Farghaly, and A. H. Naggar, J. Chem. Pharm. Res., 2018, 10, 21.

33. Annu, S. Sharma, R. Jain, and A. N. Raja, J. Electrochem. Soc., 2020, 167, 037501.

34. S. Pourbeyram, M. Soltanpour, and S. Fathalipour, Anal. Sci., 2019, 35, 739 .

35. S. Östling and P. Virtama, Acta Physiol. Scand., 1946, 11 289.

36. S. N. Prashanth, K. C. Ramesh, and J. Seetharamappa, Int. J. Electrochem., 2011, Article ID 193041, DOI: 10.4061/ 2011/193041.

37. D. K. Gosser, Jr., "Cyclic Voltammetry-Simulation and Analysis of Reaction Mechanisms", 1993, VCH, New York.

38. E. Laviron, J. Electroanal. Chem., 1979, 101, 19.

39. J. I. Gowda and S. T. Nandibewoor, Asian J. Pharm. Sci.
2014, 9, 42.

40. N. Oyama and F. C. Anson, J. Electrochem. Soc., 1980, 127,640

41. A. I. Gopalan. K.-P. Lee, K. M. Manesh, P. Santhosh, J. H. Kim, and J. S. Kang, Talanta, 2007, 71, 1774.

42. F. Scholz, ChemTexts, 2015, 1, Article 17, DOI: 10.1007/ s40828-015-0016-y.

43. R. F. Teófilo, E. L. Reis, C. Reis, G. A. da Silva, and L. T. Kubota, J. Braz. Chem. Soc., 2004, 15, 865.

44. J. Osteryoung and J. J. O’Dea, ,'Electroanalytical Chemistry. A Series of Advances”, ed. A. J. Bard, 1986, Vol. 14, Marcel Dekker, New York, 209.

45. S. Boman, Anal. Chem., 1982, 54, 698A.

46. E. J. Zachowski, M. Wojciechowski, and J. Osteryoung, Anal. Chim. Acta, 1986, 183, 47.

47. I. Švancara, K. Vytřas, J. Barek, and J. Zima, Crit. Rev. Anal. Chem., 2001, 31, 311.

48. S. S. Aher, S. Gajare, and R. B. Saudagar, Int. J. ChemTech Res., 2017, 10, 736 . 